\title{
No increased mortality in patients with rheumatoid arthritis: up to 10 years of follow up from disease onset
}

E J A Kroot, M A van Leeuwen, M H van Rijswijk, M L L Prevoo, M A Van 't Hof, L B A van de Putte, P L C M van Riel

\begin{abstract}
Objective-To investigate mortality, functional capacity, and prognostic factors for mortality in an inception cohort of patients with recently diagnosed $R A$ followed up for up to 10 years.

Methods-The observed mortality of this inception cohort with recently diagnosed RA, was analysed in relation to the expected mortality, calculated with the aid of life tables of the general population of the Netherlands (matched for age and sex). Functional capacity was measured by the Health Assessment Questionnaire. Prognostic factors for mortality were analysed multivariately by the Cox proportional hazards model.
\end{abstract}

Results-Between January 1985 and April 1997, 622 patients entered the study, and were included in the analysis of mortality. The death rate in the first 10 years of the disease was not significantly different from that of the general population. Fifty five patients from the study group died ( $16 \%$ up to 10 years of follow up). The most commonly reported causes of death were of cardiovascular and respiratory origin. The other causes of death could be classified into cancer, sepsis, amyloidosis, leukaemia, renal insufficiency of unknown cause, perforation of the oesophagus, probably related to the treatment with non-steroidal anti-inflammatory drugs, and pancytopenia during aurothioglucose treatment. Functional capacity improved significantly during the first six years compared with the value at start. Statistically significant predictors for death were age at the start and male sex.

Conclusions-In contrast with earlier studies performed, no excess mortality in the first 10 years of an inception cohort of patients with $R A$ was seen. In addition, the functional capacity was relatively constant during the first six years after an initial improvement from baseline. Age at start and male sex were the only statistically significant predictors for death. (Ann Rheum Dis 2000;59:954-958)

Rheumatoid arthritis (RA) is a systemic inflammatory disease characterised by chronic polyarthritis, which often leads to severe disability. Several studies have shown that RA is associated with an increased death rate. ${ }^{1-6}$ However, most of these studies show differ- ences in their definitions of RA, selection of patients and controls, length of follow up, duration of RA before the study, methods of statistical analyses, and the linking of causes of death ascribed to RA. ${ }^{14-8}$

Only three studies investigated mortality in inception cohorts of patients with recent onset RA (symptoms for less than one year at study entry)..$^{9-12}$ Two studies concerned patients already included before 1975, and in both studies an increased death rate was found. ${ }^{9-11}$ In contrast, in a recently published inception cohort study no increased death rate was found, but progressive functional impairment during the first years of the disease was seen in these patients. ${ }^{12} 13$

In the past decade there has been a dramatic change in the pharmacotherapy: the number of available non-steroidal anti-inflammatory drugs (NSAIDs) has increased, but probably more importantly sulfasalazine and methotrexate, the two most commonly used disease modifying antirheumatic drugs (DMARDs) at present, were introduced in the treatment of RA. In addition, DMARDs are given earlier in the disease course, sometimes even in combinations. It has been assumed that this more aggressive treatment strategy has influenced the disease course beneficially at the long term, though this has not yet been proved. ${ }^{14}$

In several studies increased death rates have been reported for infections, especially respiratory infections, gastrointestinal related deaths, and lymphoproliferative diseases. The prevalence of cardiovascular deaths and deaths from carcinomas in patients with RA has been reported to be roughly the same as in the general population. ${ }^{35915}$ We evaluated the causes of death in this present study.

In most studies the possibility of predicting mortality has also been investigated. A great variety of prognostic factors have been reported so far: age, sex, formal educational level, rheumatoid factor (RF), the presence of rheumatoid nodules at the first visit, joint count, activities of daily living, oral corticosteroid use, erythrocyte sedimentation rate (ESR), disease duration, and extra-articular manifestations of RA, particularly vasculitis. ${ }^{12-24}$ Because no consistency exists in the design of these studies, it is still unclear which variables are predictive for mortality.

In this study, which was started in 1985, the death rate, causes of death, functional disability, and possible prognostic factors for mortality were investigated in an inception cohort of 


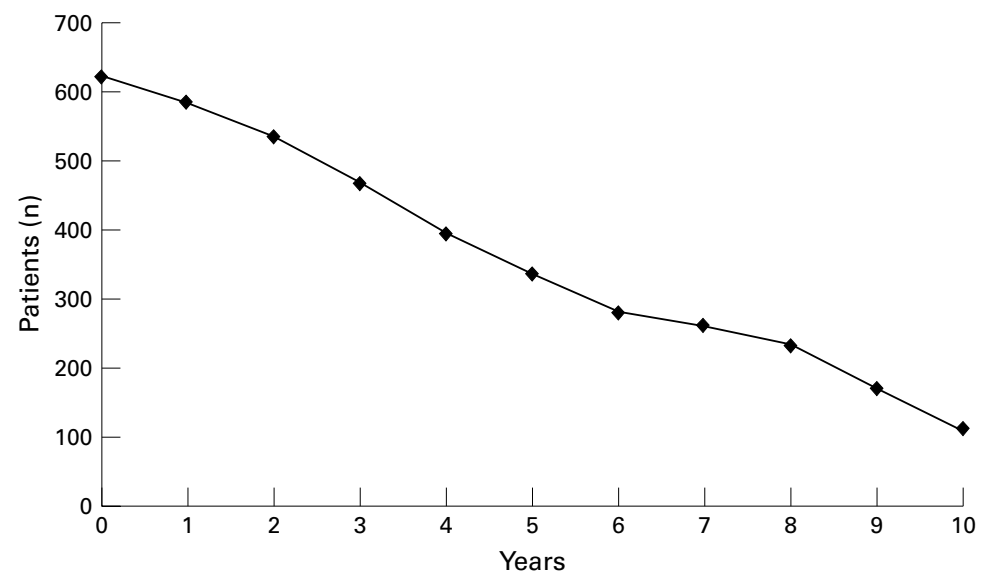

Figure 1 Length of follow up of patients with recent onset rheumatoid arthritis.

patients with recent onset RA; data were collected and new patients included until 1997.

\section{Materials and methods}

Starting January 1985, all consecutive patients attending the Nijmegen or Groningen University Hospital with recent onset RA (symptoms for $<1$ year at study entry) according to the American Rheumatism Association criteria (ARA, 1987), were asked to participate in a long term prospective study. All patients were followed up in a standardised way and new patients were included ${ }^{25}$ up to April 1997. The patients were treated by different rheumatologists of both departments, and were seen every three months by specially trained research nurses. Quantitative clinical and laboratory data were collected, comprising the Ritchie Articular Index (RAI), the number of tender joints, number of swollen joints, ESR (according to Westergren, $\mathrm{mm} / 1 \mathrm{st} h$ ), IgM $\mathrm{RF}$ (enzyme linked immunosorbent assay (ELISA), normal <10 IU/ml), HLA status, and level of education. Furthermore, the patients completed a Health Assessment Questionnaire (HAQ) every six months and at each visit the disease activity score (DAS) was calculated. ${ }^{26}{ }^{27}$ The starting date, dose, stopping date, reason for discontinuation, and side effects of the DMARDs and NSAIDs used were recorded. ${ }^{28}$ DMARDs included antimalarial drugs, methotrexate, sulfasalazine, gold, D-penicillamine, azathioprine, cyclophosphamide, and cyclosporin.

Standard methods of survival analysis (Kaplan-Meier, 1957) were used, in which the mortality of this RA group $(n=622)$ was compared with the expected mortality based on the general population of the Netherlands, matched for age and sex..$^{29}$ Patients lost to follow up were contacted by phone or mail with the help of family or general physicians to determine the death/life status of the relevant patient at April 1997. Causes and dates of death were obtained from the general practitioner (or rheumatologist who obtain dates and causes of death from the general practitioner in the Netherlands) and were coded according to the International Classification of Diseases, ninth revision, clinical modification (ICD-9$\mathrm{CM}$ ) medical diagnoses.
Table 1 Baseline characteristics of the study group

\begin{tabular}{ll}
\hline Characteristic & Patients $(n=622) *$ \\
\hline Female & $386(62)$ \\
Age at study start (years) & $53.3(18-86)$ \\
IgM RF+ $>10 \mathrm{IU})$ & $510(82)$ \\
HLA-DR4+ & $336(54)$ \\
ESR + (mm/1st hour) & $40.7(2.0-135.0)$ \\
Disease activity score & $4.0(2.8-5.6)$ \\
Ritchie Articular Index & $12.3(3.0-27.0)$ \\
Health Assessment Questionnaire & $0.67(0-1.97)$ \\
DMARD (first year) & $566(91)$ \\
DMARD (follow up) & $591(95)$ \\
Corticosteroids (first year) & $124(20)$ \\
Corticosteroids (follow up) & $212(34)$ \\
\hline${ }^{\star}$ Mean values (range) and numbers (percentages) are given. \\
†ESR = erythrocyte sedimentation rate; DMARD = disease \\
modifying antirheumatic drug.
\end{tabular}

The functional capacity of patients attending the Nijmegen University Hospital $(n=322)$, for whom Health Assessment Questionnaires were available at each year of follow up $(n=249)$, are presented for each year of the follow up (table 2).

Prognostic factors for mortality were analysed multivariately by the Cox proportional hazards model, multivariate with age (start of RA), sex (male or female), IgM rheumatoid factor (IgM RF positive or negative), HLA status, RAI, number of swollen joints (range 0-44), mean DAS of first year of follow up (range 0-10), and ESR fixed in the model. All variables were continuous, except sex, IgM RF, and HLA status. Patients for whom all baseline characteristics were available were included in the model $(n=566)$. The dependent variable in the model was duration of follow up. In a separate analysis the mean HAQ of the first year was included in the Cox proportional hazards model as well.

\section{Results}

MORTALITY AND FUNCTIONAL CAPACITY

By April 1997622 patients had entered the study and were included in the various analyses. Table 1 presents the baseline characteristics of the clinical variables of the study group. Figure 1 shows the number of patients at each time point during 10 years of follow up. Mean duration of follow up was 5.8 years (range 1-10), and 109 patients were followed up for 10 years. Of the total study group of 622 patients with recently diagnosed RA, 55 patients ( $16 \%$ of the patients up to 10 years of follow up) died during the period of observation with a mean age at death of 73 years. The patients included had a similar prevalence of chronic comorbidities as patients with other chronic diseases, also having other comorbidities, living in the same area as the patients with RA. ${ }^{30} 31$ The life/death status could not be traced in two of the 35 patients who were lost to follow up at April 1997.

The causes of death ascribed by the rheumatologists or general practitioners could be classified as cardiovascular $(n=26)$ and respiratory cause $(n=6)$, cancer $(n=17)$, sepsis $(n=1)$, amyloidosis $(n=2)$, renal insufficiency of unknown cause $(n=1)$, perforation of the oesophagus, probably related to NSAID treatment $(n=1)$, and pancytopenia during aurothioglucose treatment $(n=1)$. 


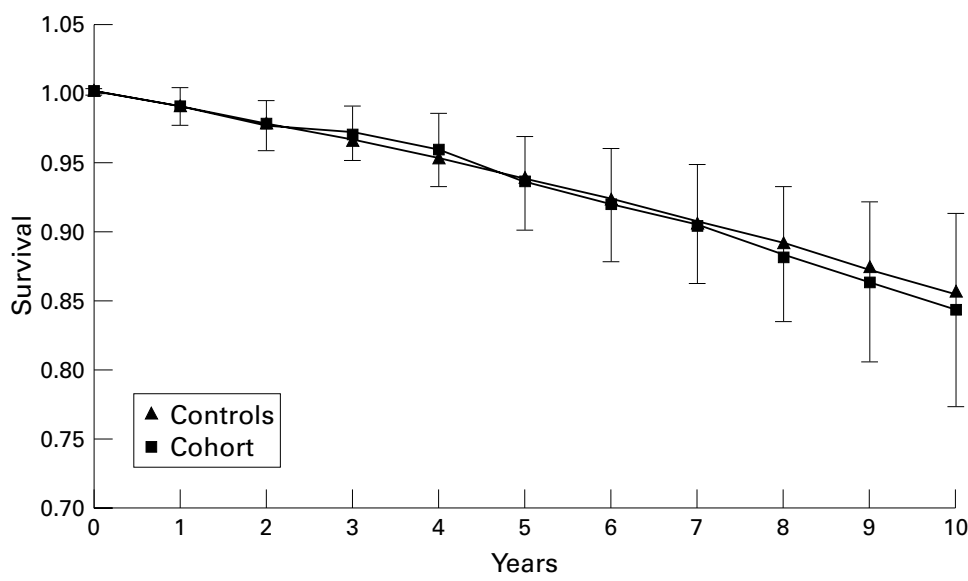

Figure 2 Kaplan-Meier survival curves of patients with recent onset rheumatoid arthritis compared with the general population of the Netherlands, matched for age and sex.

Confidence intervals (95\%) of the study group are shown.

Figure 2 presents survival functions (Kaplan-Meyer) of the patients with RA $(n=622)$ compared with the general population of the Netherlands, matched for age and sex. Confidence intervals (95\%) are shown for the study group, as patients had to be censored for duration of follow up, because of different inclusion dates of the patients. The death rate was not significantly different from that of the general population of the Netherlands up to 10 years of RA. The survival curves started to diverge at about seven years of follow up, though this was not statistically significant.

Table 2 shows the course of the functional capacity according to the HAQ during the complete follow up period of the patients attending the Nijmegen University Hospital. The mean value of the HAQ of these patients at entry was comparable with the mean value of the patients not included in the analysis for functional disability. The functional capacity was relatively constant during the first six years after an initial improvement from baseline. Thereafter a gradual decline in HAQ scores was seen, with the functional capacity being at the same level after 10 years of follow up as at the start.

PROGNOSTIC FACTORS

Patients for whom all baseline characteristics were available were included in the model $(n=566)$. Table 3 presents the results. Age at the start $(p=0.0001)$ and male sex $(p=0.02)$

Table 2 Course of the functional capacity (Health Assessment Questionnaire (HAQ) scores) during 10 years of follow up

\begin{tabular}{lllll}
\hline Year & $\begin{array}{l}\text { HAQ } \\
\text { (mean) }\end{array}$ & $\begin{array}{l}\text { Mean difference } \\
\text { compared with baseline }\end{array}$ & SEM $\dagger$ & $n$ \\
\hline At entry & 0.67 & 0 & & 249 \\
1 & 0.49 & $-0.25^{\star}$ & 0.04 & 210 \\
2 & 0.55 & $-0.23^{\star}$ & 0.04 & 201 \\
3 & 0.53 & $-0.24^{\star}$ & 0.04 & 168 \\
4 & 0.56 & $-0.18^{\star}$ & 0.05 & 151 \\
5 & 0.55 & $-0.19^{\star}$ & 0.05 & 127 \\
6 & 0.56 & $-0.10^{\star}$ & 0.05 & 110 \\
7 & 0.63 & -0.01 & 0.06 & 98 \\
8 & 0.65 & -0.01 & 0.06 & 78 \\
9 & 0.63 & -0.07 & 0.07 & 44 \\
10 & 0.65 & -0.05 & 0.07 & 40 \\
\hline${ }_{\mathrm{p}}<0.05$ & & & &
\end{tabular}

†SEM $=$ standard error of the mean.
Table 3 Results of multivariate Cox regression analyses of the prognostic values of selected variables at study entry in patients with rheumatoid arthritis

\begin{tabular}{lll}
\hline Variables & $\begin{array}{l}\text { Risk ratio } \\
\text { (conditional) }\end{array}$ & p Value \\
\hline Sex (male sex) & 0.56 & 0.02 \\
Age (at study start) & 1.12 & 0.0001 \\
IgM RF & 2.51 & 0.06 \\
HLA-DR4+ & 0.85 & 0.57 \\
ESR & 0.99 & 0.18 \\
Disease Activity Score & 2.69 & 0.12 \\
Ritchie Articular Index & 0.95 & 0.29 \\
Total swollen joints & 0.94 & 0.21 \\
\hline
\end{tabular}

${ }^{\star} \mathrm{ESR}=$ erythrocyte sedimentation rate

were the only significant prognostic factors for death. IgM RF, though not statistically significant, appeared to have some prognostic power $(p=0.06)$. The level of education proved to be lower in the RA cohort than in the Dutch working or the Dutch general population, but after adjustment for age and sex the difference disappeared..$^{32}$ None of the other variables was a statistically significant prognostic factor.

In a separate analysis, in which the mean HAQ of the first year was also included, the HAQ did not have prognostic value for mortality (results not shown).

\section{Discussion}

In this prospective study, started in 1985, the death rate of an inception cohort of patients with recent onset RA was analysed. Fifty five patients of the study group of 622 patients died during the period of observation. The observed mortality of this study group up to 10 years of follow up was comparable with the expected mortality, calculated with the aid of life tables, of the general population of the Netherlands (matched for age and sex). ${ }^{29}$ This finding is in contrast with the general belief that RA is associated with an increased death rate. ${ }^{33}$

Only three studies report the mortality in patients followed up prospectively from onset. $^{9-12}$ In the study of Corbett et al a small increase in mortality, compared with population expected rates, was found (these data were not analysed statistically). ${ }^{9}$ This excess mortality increased with increasing duration of disease, but was already apparent after three years of follow up. ${ }^{9}$ The study of Rasker and Cosh, also including an inception cohort of patients with RA who satisfied the ARA criteria of definite or classical RA within one year of onset, did not compare their results with the general population (that is, the population of the UK). However, an increase in mortality, between the third and tenth year after baseline with a loss of life expectancy of at least five years was suggested. ${ }^{11}$ A striking difference between the study of Rasker and Cosh and our data is the mean age at death (73 years in this study $v 68$ years in the study of Rasker et al). In contrast, only the study of Lindquist and Eberhardt found no increased mortality. ${ }^{12}$

The causes of death observed in our study were comparable with the results seen in the three inception cohort studies, except for two deaths related to treatment which occurred in this study..$^{9112}$ In the three previous studies second line drugs were not responsible for any 
deaths, probably owing to the relatively small numbers of patients in those studies. ${ }^{91112}$ In the study of Lindquist and Eberhardt only $62 \%$ of the patients were treated with DMARDs and $16 \%$ with oral corticosteroids at some time during follow up. ${ }^{12}$ In our study $91 \%$ of the patients were already being treated with DMARDs during the first year of follow up and $95 \%$ of the patients were treated with DMARDs at some time during follow up. In addition, $20 \%$ of the patients used oral corticosteroids at some time during the first year of observation, and $35 \%$ of the patients used oral corticosteroids at some time during the complete follow up period. In the Netherlands there is a general policy of referring patients with RA early in the disease course to a rheumatologist. Therefore none of the patients had started taking DMARDs or corticosteroids before inclusion in the study. Although it seems logical to suggest that the early use of second line treatment might lead to treatment related mortality, ${ }^{34}$ this was not confirmed by our study as no increased mortality was found. In other mortality studies increased death rates in patients with RA were reported as a result of infection, especially respiratory infection, gastrointestinal and lymphoproliferative diseases. ${ }^{1}{ }^{2335-40}$ However, most of these studies had different definitions of RA, disease duration before study inclusion, and length of follow up, and most patients received steroid treatment for several years. ${ }^{12} 3738$

The functional capacity was relatively constant during the first six years after an initial improvement from baseline. After 10 years of follow up the functional capacity had returned to the level at the start of the study. This is in contrast with the study of Corbett et al, in which disability was reported to develop most rapidly during the first year after disease onset, with a slow, nearly linear rate of increase during the period of observation. ${ }^{9}$ In the study of Eberhardt and Fex, in which no increased mortality was found in an inception cohort of patients with RA, it was concluded that functional impairment of different joints had progressed, but most patients were mildly disabled up to six years of follow up. ${ }^{13}$ In that study fewer patients were treated with second line drugs or corticosteroids during follow up, and therefore we suggest that the early use of second line treatment in our study, in almost all patients, might have led to improved functional capacity but not to increased mortality.

Different variables at onset were also analysed for their prognostic value for mortality. No univariate analysis was performed, as mortality and several disease activity variables are highly age and sex related. Therefore age would act as a confounder in a univariate analysis. In the regression model only age at start and male sex were statistically significant prognostic factors. These results are in line with the results of the study of Lindquist and Eberhardt. ${ }^{12}$ This is unsurprising, as age and sex are the strongest predictors of mortality in the general population as well. However, Anderson, who reviewed 25 articles on age and mortality in RA, failed to show a clear association between sex, age, and mortality in RA. ${ }^{41}$ Corbett et al and Rasker and Cosh did not analyse prognostic factors for mortality. Corbett et al showed that, compared with survivors, those who died had more severe disease, were more often treated with steroids, and became more disabled during the course of their illness. ${ }^{9}$ Rasker and Cosh suggested a longer life expectancy for women, a greater chance of early death for patients with a bad functional status and for patients with persistently high ESR and with strong seropositivity for RF. ${ }^{11}$ However, these suggestions were not analysed statistically.

It has long been suggested that patients with RA, especially the more severe cases, have a shortened life expectancy compared with the general population. ${ }^{11}$ In this study of an inception cohort of patients with recent onset RA we conclude that the death rate up to 10 years of follow up of patients with RA was not significantly different from the expected mortality of the general population. Therefore we suggest that the aggressive therapeutic strategies introduced since the 1980s have not only resulted in an improved disease course but also in a better long term outcome. But we are aware that other possibilities cannot be excluded-for example, some evidence suggesting that RA is getting milder and less common and the fact that patients attending hospitals are more likely to receive preventive treatment for comorbidities. However, as some studies have suggested that the mortality of patients with RA compared with the general population increases with the duration of the disease, further research (longer follow up) may be necessary. ${ }^{9}$ In this study only age at the start and male sex were statistically significant prognostic factors for mortality.

We are grateful to all patients for completing the various assessments. We thank our rheumatology research nurses, D van den
Akker, A ter Avest, J Deenen, and L Theunisse, for their assistance in data collection.

This study was supported by a grant from "Het Nationaal Reumafonds" of the Netherlands (The Dutch League against Rheumatism)

1 Mitchell DM, Spitz PW, Young DY, Bloch DA, McShane DJ, Fries JF. Survival, prognosis, and causes of death in heumatoid arthritis. Arthritis Rheum 1986;29:706-14.

2 Vandenbroucke JP, Hazevoet HM, Cats A. Survival and cause of death in rheumatoid arthritis: a 25-year prospective followup. J Rheumatol 1984;11:158-61.

3 Leigh JP, Fries JF. Arthritis and mortality in the epidemiological follow-up to the National Health and Nutrition Examination Survey I. Bull N Y Acad Med 1994;71:69 86.

4 Symmons DP, Jones MA, Scott DL, Prior P. Longterm mortality outcome in patients with rheumatoid arthritis: early presenters continue to do well. J Rheumatol 1998;25: early prese

5 Gabriel SE, Crowson CS, O'Fallon WM. Mortality in rheumatoid arthritis: have we made an impact in 4 decades? J Rheumatol 1999;26:2529-33.

6 Pincus T, Callahan LF, Sale WG, Brooks AL, Payne LE, Vaughn WK. Severe functional declines, work disability, and increased mortality in seventy-five rheumatoid arthritis patients studied over nine years. Arthritis Rheum 1984;27: $864-72$

7 Pincus T, Callahan LF. Quantitative measures to assess, monitor and predict morbidity and mortality in rheumatoid arthritis. Baillieres Clin Rheumatol 1992;6:161-91.

8 Symmons DP. Mortality in rheumatoid arthritis. Br J Rheumatol 1988;27(suppl 1):44-54.

9 Corbett M, Dalton S, Young A, Silman A, Shipley M. Factors predicting death, survival and functional outcome in a tors predicting death, survival and functional outcome in a prospective study of early rheumatoid disease over fifteen
years. Br J Rheumatol 1993;32:717-23.

10 Rasker JJ, Cosh JA. The natural history of rheumatoid arthritis over 20 years. Clinical symptoms, radiological signs, treatment, mortality and prognostic significance of signs, treatment, mortality and prognostic significance
early features. Clin Rheumatol 1987;6(suppl 2):5-11. 
11 Rasker JJ, Cosh JA. Cause and age at death in a prospective study of 100 patients with rheumatoid arthritis. Ann study of 100 patients with
Rheum Dis $1981 ; 40: 115-20$.

12 Lindquist E, Eberhardt K. Mortality in rheumatoid arthritis patients with disease onset in the 1980s. Ann Rheum Dis 1999;58:11-14

13 Eberhardt KB, Fex E. Functional impairment and disability in early rheumatoid arthritis -development over 5 years. J Rheumatol 1995;22:1037-42.

14 Myllykangas Luosujarvi R, Aho K, Isomaki H. Death attributed to antirheumatic medication in a nationwide series of 1666 patients with rheumatoid arthritis who have died. J Rheumatol 1995;22:2214-17.

15 Baecklund E, Ekbom A, Sparen P, Feltelius N, Klareskog L. Disease activity and risk of lymphoma in patients with rheumatoid arthritis: nested case-control study. BMJ 1998; 317:180-1.

16 Leigh JP, Fries JF. Mortality predictors among 263 patients with rheumatoid arthritis. J Rheumatol 1991;18:1307-12.

17 Pincus T, Callahan LF, Vaughn WK. Questionnaire, walking time and button test measures of functional capacwalking time and button test measures of functional capacity as predictive markers for mortality

18 Pincus T, Callahan LF. Taking mortality in rheumatoid arthritis seriously - predictive markers, socioeconomic status and comorbidity. J Rheumatol 1986;13:841-5.

19 Pincus T, Callahan LF. Formal education as a marker for increased mortality and morbidity in rheumatoid arthritis. Journal of Chronic Disease 1985;38:973-84.

20 Callahan LF, Pincus T. Mortality in the rheumatic diseases. Arthritis Care Research 1995;8:229-41.

21 Pincus $\mathrm{T}$. Long-term outcomes in rheumatoid arthritis. $\mathrm{Br} J$ Rheumatol 1995;34(suppl 2):59-73.

22 Furst DE. Predictors of worsening clinical variables and outcomes in rheumatoid arthritis. Rheum Dis Clin North Am 1994;20:309-19.

23 Wolfe F, Mitchell DM, Sibley JT, Fries JF, Bloch DA, Williams CA, et al. The mortality of rheumatoid arthritis. Williams CA, et al. The mortality

24 Erhardt CC, Mumford PA, Venables PJ, Maini RN. Factors predicting a poor life prognosis in rheumatoid arthritis: an 13.

25 Prevoo ML, van 't Hof MA, Kuper HH, van Leeuwen MA, van de Putte LB, van Riel PL. Modified disease activity scores that include twenty-eight-joint counts. Development and validation in a prospective longitudinal study of patients with rheumatoid arthritis. Arthritis Rheum 1995; 38;44-8.

26 van der Heijde DMFM, van 't Hof MA, van Riel PLCM, Theunisse LA, Lubberts EW, van Leeuwen MA, et al. Judging disease activity in clinical practice in rheumatoid arthritis: first step in the development of a disease activity score. Ann Rheum Dis 1990;49:916-20.
27 van der Heijde DMFM, van Riel PLCM, van de Putte LBA. Sensitivity of a Dutch Health Assessment Questionnaire in a trial comparing hydroxochloroquine vs. sulphasalazine. Scand J Rheumatol 1990;19:81-6.

28 van Riel PLCM, van Gestel AM, van de Putte LBA. Longterm usage and side-effect profile of sulphasalazine in rheumatoid arthritis. Br J Rheumatol 1995;34(suppl 2):40-2.

29 Anonymous. Life tables 1990-1994. Rijswijk: Centraal bureau voor de statistiek, 1997. (Abstract.)

30 Schellevis FG, Van der Velden J, van de Lisdonk E, Van Eijk JT, Van Weel C. Comorbidity of chronic diseases in general practice. J Clin Epidemiol 1993;46:469-73.

31 Kroot EJA, Albers J, van de Putte LBA, van Riel PLCM. Prevalence of chronic unrelated diseases in patients with rheumatoid arthritis [abstract]. Arthritis Rheum 1998; 41(suppl):S1046.

32 Albers JMC, Kuper HH, van Riel PLCM, Prevoo ML, van t Hof MA, van Gestel AM, et al. Socio-economic consequences of rheumatoid arthritis in the first years of the disease. Rheumatology 1999;38:423-30.

33 Hilliquin P, Menkes C. Rheumatoid arthritis: evaluation and management: early and established disease. In: Klippel JH, Dieppe PA, eds. Rheumatology. St Louis: Mosby, 1994; 3:13.1.

34 van de Putte LBA, van Gestel AM, van Riel PLCM. Early reatment of rheumatoid arthritis: rationale, evidence, and implications. Ann Rheum Dis 1998;57:511-12.

35 Myllykangas Luosujarvi RA, Aho K, Isomaki HA. Mortality in rheumatoid arthritis. Semin Arthritis Rheum 1995;25: 193-202.

36 Allebeck P. Increased mortality in rheumatoid arthritis. Scand J Rheumatol 1982;11:81-6.

37 Coste J, Jougla E. Mortality from rheumatoid arthritis in France, 1970-1990. Int J Epidemiol 1994;23:545-52.

38 Jones M, Symmons D, Finn J, Wolfe F. Does exposure to immunosuppressive therapy increase the 10 year malignancy and mortality risks in rheumatoid arthritis? A matched cohort study. Br J Rheumatol 1996;35:738-45.

39 Myllykangas Luosujarvi R, Aho K, Kautiainen H, Isomaki $\mathrm{H}$. Shortening of life span and causes of excess mortality in a population-based series of subjects with rheumatoid arthritis. Clin Exp Rheumatol 1995;13:149-53.

40 Wallberg Jonsson S, Ohman ML, Dahlqvist SR Cardiovascular morbidity and mortality in patients with seropositive rheumatoid arthritis in northern Sweden. J Rheumatol 1997;24:445-51.

41 Anderson ST. Mortality in rheumatoid arthritis: do age and gender make a difference? Semin Arthritis Rheum $1996 ; 25: 291-6$. 